\title{
Shift work and circadian dysregulation of reproduction
}

\author{
Karen L. Gamble ${ }^{1}$, David Resuehr ${ }^{2}$ and Carl Hirschie Johnson ${ }^{3}$ * \\ ${ }^{1}$ Department of Psychiatry and Behavioral Neurobiology, University of Alabama at Birmingham, Birmingham, AL, USA \\ ${ }^{2}$ Department of Cell and Developmental and Integrative Biology, University of Alabama at Birmingham, Birmingham, AL, USA \\ ${ }^{3}$ Department of Biological Sciences, Vanderbilt University, Nashville, TN, USA
}

\section{Edited by:}

James Olcese, Florida State

University, USA

Reviewed by:

Ted H. Elsasser, United States

Department of Agriculture, USA

Jari Rossi, University of Helsinki,

Finland

*Correspondence:

Carl Hirschie Johnson, Department of

Biological Sciences, Vanderbilt

University, 46521 st Avenue South,

Nashville, TN 37235, USA

e-mail: carl.h.johnson@vanderbilt.edu
Health impairments, including reproductive issues, are associated with working nights or rotating shifts. For example, shift work has been associated with an increased risk of irregular menstrual cycles, endometriosis, infertility, miscarriage, low birth weight or pre-term delivery, and reduced incidence of breastfeeding. Based on what is known about circadian regulation of endocrine rhythms in rodents (and much less in humans), the circadian clock is an integral regulatory part of the reproductive system. When this 24-h program is disordered by environmental perturbation (such as shift work) or genetic alterations, the endocrine system can be impaired. The purpose of this review is to explore the hypothesis that misalignment of reproductive hormones with the environmental light-dark cycle and/or sleep-wake rhythms can disrupt menstrual cycles, pregnancy, and parturition. We highlight the role of the circadian clock in regulating human reproductive physiology and shift work-induced pathology within each step of the reproductive axis while exploring potential mechanisms from the animal model literature. In addition to documenting the reproductive hazards of shift work, we also point out important gaps in our knowledge as critical areas for future investigation. For example, future studies should examine whether forced desynchronization disrupts gonadotropin secretion rhythms and whether there are sleep/wake schedules that are better or worse for the adaptation of the reproductive system to shift work. These studies are necessary in order to define not only whether or not shift work-induced circadian misalignment impairs reproductive capacity, but also to identify strategies for the future that can minimize this desynchronization.

Keywords: endocrinology, pregnancy failure, misalignment, sleep, circadian disruption, infertility

\section{INTRODUCTION}

The National Sleep Foundation 2008 poll estimates that $\sim 7 \%$ of American workers are shift workers (1), and the U.S. Bureau of Labor Statistics estimates that nearly $15 \%$ of the workforce is employed on an alternative work schedule such as evening, night, or rotating shift work (2). Shift work is associated with an increased risk of developing cardiovascular/metabolic/gastrointestinal disorders, some types of cancer, and mental disorders including depression and anxiety (3-5). In women, shift workers have a higher incidence of obesity and high blood pressure (6), breast cancer (7), and reproductive issues (8-10). For example, shift work has been associated with an increased risk of irregular menstrual cycles (11), endometriosis (12), miscarriage (13), low birth weight or pre-term delivery $(14,15)$, and reduced incidence of breastfeeding (16). The purpose of this review is to highlight the role of circadian clock in regulating human reproductive physiology and shift work-induced pathology within each step of the reproductive axis.

The circadian clock allows organisms to anticipate regular and daily repeating events that occur at approximately the same time of day, and this anticipation enables upregulation of key physiological pathways so that an appropriate physiological or behavioral response can be elicited at the correct time. In mammals, these 24-h rhythms in physiology are orchestrated by a primary clock in the suprachiasmatic nucleus (SCN) of the hypothalamus. The SCN coordinates other central circadian oscillators (e.g., the hypothalamus and pituitary gland) that drive rhythms in peripheral tissues (17), including endocrine tissues such as the adrenal gland, thyroid gland, adipocytes, pancreas, and gonads (18). (For an overview of basic human reproductive endocrinology, see Box 1). Within both the central clocks in the brain and peripheral oscillators, the 24 -h timing mechanism appears to be the same and is composed of a set of genes (clock genes) and respective proteins that form a feedback loop [for review see (19)] which rhythmically regulates many output genes (clock-controlled genes or ccg's) as detailed in Box 2. For the purpose of this review, we will focus on the circadian clock genes CLOCK, NPAS2, BMAL1 (a.k.a. ARNTL), PER1, and PER2.

The circadian rhythms of clock-gene expression observed in reproductive brain areas suggest that this neural timing system drives and orchestrates neuroendocrine events ultimately leading up to the pre-ovulatory luteinizing hormone (LH) surge and ovulation [reviewed by (18)]. The SCN has been shown to be necessary for normal functioning of the hypothalamic pituitary gonadal (HPG) axis, and rhythms of clock-gene expression have been recorded in brain regions controlling both the HPG and hypothalamic-pituitary-adrenal (HPA) axes. The earliest and best described circadian oscillator in the HPG axis is the pituitary gland (18). Here, rhythmic gene expression of prolactin and gonadotropin releasing hormone $(\mathrm{GnRH})$ receptors has been shown to be mediated via clock-gene regulatory elements 


\section{Box 1 | Basic reproductive physiology overview.}

Female mammals exhibit a cyclical flux of hormones controlling follicular maturation and ovulation. The approximately 28-day menstrual cycles of women are tightly orchestrated by the HPG axis, which coordinates peripheral organs with the central nervous system (CNS). The primary signal from the CNS is $\mathrm{GnRH}$, which is secreted in short pulses averaging once every $90 \mathrm{~min}$. GnRH also stimulates the anterior pituitary to release FSH and LH, which promote follicular development. Estradiol is produced by developing follicles in the ovaries; its synthesis is a carefully regulated system that is coordinated by feedback mechanisms between the hypothalamus, anterior pituitary, and ovaries. The release of estradiol from developing ovarian follicles stimulates proliferation of the uterine endometrium and negatively regulates the further release of $\mathrm{GnRH}$ and $\mathrm{FSH}$. One follicle outgrows all of the others which undergo atresia. As estradiol concentrations peak, they trigger the surge release of $\mathrm{GnRH}$ into the hypophyseal portal blood system. This $\mathrm{GnRH}$ surge triggers a surge of LH which acts on the ovary and induces ovulation. The follicle releases the ovum as it ruptures and undergoes luteinization. During this, the secretory cycle stage, large amounts of progesterone and estradiol are secreted by the corpus luteum. The secretory phase lasts for 10-16 days in women. During this phase the endometrium becomes increasingly thicker as endometrial glands and blood vessels become increasingly tortuous in preparation for implantation of a fertilized ovum. Simultaneously, estrogen in particular and progesterone to a lesser extent negatively feed back to the anterior pituitary and maintain low secretory rates of LH and FSH. In the absence of pregnancy, involution of the corpus luteum usually occurs after the 12th day. The sudden cessation of its inhibitory effect on the anterior pituitary allows for the renewed release of LH and FSH to begin a new ovarian cycle. At the same time, paucity of secretion of progesterone and estradiol lead to the breakdown of endometrial lining and menstruation.

\section{Box 2 | The molecular circadian clock.}

(A) The 24-h timing of the molecular clock is orchestrated by a set of clock genes and proteins that form a positive feedback loop when CLOCK dimerizes with BMAL1 and binds to the E-box elements of PER and CRY genes, activating transcription. Negative control of transcription occurs when $P E R / C R Y$ dimerize, and this complex translocates into the nucleus where it inhibits the transcription of its own genes, through inhibition of BMAL1 and CLOCK transcription.

Circadian clock-gene expression is rhythmic in peripheral tissues, including in human PBMCs (49-52) with $h P E R 1 / 2$ peaking at the sleep-to-wake transition and $h B M A L 1$ peaking at the end of the wake period (53). (B) Circadian clock-gene expression has been reported in a majority of neuroendocrine tissues (86). The neural timing of the SCN is believed to signal to neuroendocrine cells (e.g., hypothalamic $\mathrm{GnRH}$ neurons) which in turn (via GnRH) drive the rhythmic secretion of pituitary LH and subsequent ovulation. Rhythms of clock-gene expression have in fact been reported in many brain regions involved in controlling the HPG axis, such as the hypothalamus and the pituitary gland, the latter being the earliest and best described circadian oscillator in the HPG axis $(21,87,88)$. Several peripheral mammalian reproductive tissues in both male [e.g., extra-testicular ducts (89)] and female [e.g., ovary, uterus, and oviducts (45, 90-94)] rodents have also been shown to exhibit 24-h oscillations in circadian clock-gene expression and circadian clock-controlled gene expression rhythms [for review, see (23)]. For example, in the ovary, the transcriptional rhythms of the circadian clock genes per1/2 and bmal1 peak around light offset and onset, respectively, regardless of ovarian cycle stage $(8,23)$.

A

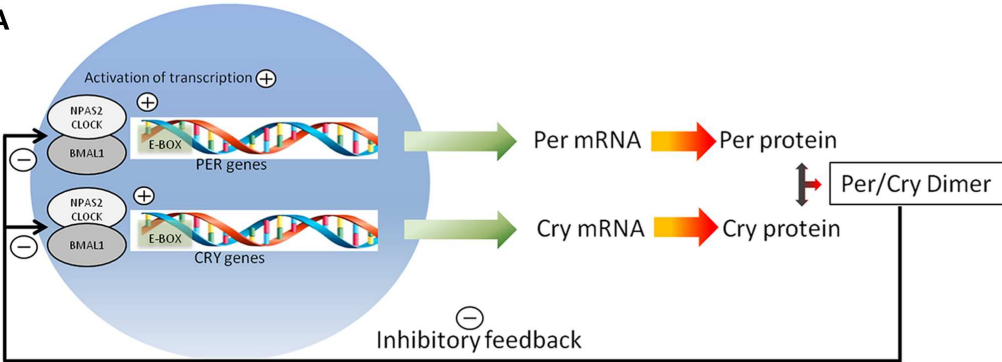

Approx. 24h cycles

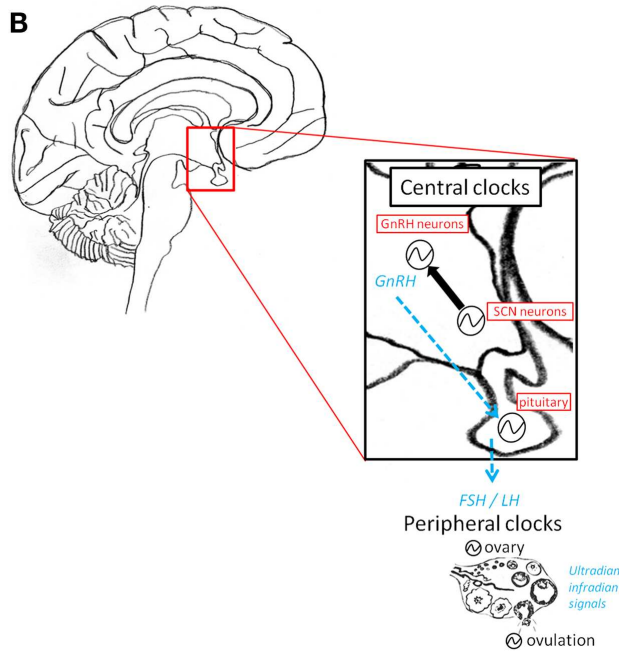

[i.e., E-Boxes; (20,21)]. Furthermore, GnRH secreted by the hypothalamus appears to activate clock-gene expression in pituitary gonadotrophs through the same intracellular mechanism used to drive LH gene expression (22). In the more distally located ovarian clock, CLOCK and BMAL1 transcriptionally regulate a clockcontrolled gene whose protein product is a key transcription factor (COX2) involved in prostaglandin synthesis (23). This growing body of work linking circadian and reproductive systems supports 
the notion that the coordinated timing of circadian clocks in reproductive brain areas such as the hypothalamus, forebrain, and pituitary and more peripheral circadian oscillators in the gonads may not only facilitate but be a prerequisite for establishment and maintenance of reproductive health.

Endogenous rhythmicity must be entrained or synchronized to the environment, and this process primarily occurs through photic input to the SCN from the retina. Specifically, environmental light is detected in intrinsically photoreceptive, melanopsin-containing retinal ganglion cells, which transmit this information directly to the SCN via the dedicated retinohypothalamic tract (24). Through a multi-synaptic pathway, the SCN drives 24 -h rhythms in the production of the pineal hormone melatonin and is also critical for acute, light-induced suppression of melatonin synthesis at night $(25,26)$. Other environmental stimuli including exercise and feeding behavior can also entrain circadian rhythmicity. For example, when rodents consume food $12 \mathrm{~h}$ out of phase with activity rhythms, the rhythmic clock-gene expression in the SCN remains the same while clock-gene expression shifts in the liver, kidney, heart, and pancreas, leading to a state of internal desynchronization $(27,28)$. In addition, transient internal desynchronization induced by a 6-h delay of the light-dark cycle in rats alters sleep architecture (29). In fact, even a simple 6-h shift in the light-dark cycle takes 6-12 days for clock-gene expression rhythms to completely adjust, with different peripheral tissues requiring varying amounts of time to shift $(30,31)$. Detailed investigation of the effects of a $6 \mathrm{~h}$ advance of the light-dark cycle on ovarian rhythmic phase has revealed that the ovarian clock is not fully shifted by 6 days, but phase synchrony is fully restored by 12 days. Moreover, endocrine signals from the pituitary [LH and follicle stimulating hormone (FSH)] are capable of resetting the ovarian clock phase (31). In addition to transient desynchronization, chronic internal desynchronization using repeated, weekly $6 \mathrm{~h}$ advances in the light-dark cycle in rodents, can result in greatly increased mortality in aged or immune-challenged animals $(32,33)$. Given that shift workers commonly prefer to shift back to night-sleep on days-off (34), a better understanding of the internal desynchronization of endocrine tissues induced by frequent shifts in sleep/wake behavior is critically important to finding solutions to the reproductive health hazards of shift work.

\section{CIRCADIAN REGULATION OF FERTILITY CIRCADIAN CLOCK REGULATION IN ENDOCRINOLOGY AND IN REPRODUCTIVE TISSUES}

In the 1960s, Aschoff elegantly demonstrated that body temperature, urine excretion, and sleep/wake patterns in humans exhibit a circadian rhythm (i.e., persistence of time-of-day-dependent rhythms when environmental cues remain constant) (35). Since that time, numerous studies have also reported circadian regulation of plasma cortisol levels in humans, including the persistence of a $\sim 24$-h rhythm even when participants maintain a 28 -h behavioral day, inducing desynchrony of circadian and sleep/wake behavioral cycles. It is interesting to note that despite the primary clock rhythm being $\sim 24 \mathrm{~h}$ (truly circadian), many endocrine rhythms underlying its regulation are either ultradian (shorter than 24 h; e.g., 90-min GnRH pulses) or infradian (longer than 24 h; e.g., 28-day LH surge). In any case, these endogenous, central, clock-controlled rhythms are important because previous studies have shown that peak cortisol levels in the morning (cortisol awakening response) correlate with the timing of the LH surge, which typically peaks at the end of the sleep episode $(36,37)$ consistent with rodent models [see (38) for review]. Indeed, an intact central clock in the SCN has been shown to be necessary for the LH surge and subsequent ovulation (39). In addition to $\mathrm{LH}$, serum concentrations of $\mathrm{FSH}$, estrogen or $17 \beta$-estradiol (E2), and progesterone (P4) show significant time-of-day variation $(37,40)$ and increase shortly after awakening specifically in women with regular menstrual cycles in the estradiol (E2) dependent proliferative phase and progesterone (P4) dependent secretory phase (41). However, one recent study found that estradiol, $\mathrm{LH}, \mathrm{FSH}$, and glycoprotein free $\alpha$-subunit did not exhibit a circadian rhythm in young, healthy, normal cycling women in the proliferative phase living on a constant routine in the absence of environmental time cues (42). Given the vast amount of literature on circadian regulation of endocrine rhythms in rodents $(8,10,18)$, it is surprising how little is known about circadian regulation of human endocrine rhythms, as noted in (8). It will be important for future circadian rhythm studies to distinguish between effects of the circadian clock and sleep on endocrine rhythmicity because partial sleep deprivation can modulate thyroid stimulating hormone, prolactin, LH, and estradiol (43).

A hint that the circadian molecular clock is regulating time-ofday-dependent variation in the reproductive hormones that affect fertility are the recent findings that a polymorphism in the circadian clock-gene ARNTL (rs2278749) confers increased risk of miscarriages, and a polymorphism (rs11673746) in the circadian clock-gene NPAS2 (a CLOCK homolog) may be protective and is associated with decreased incidence of miscarriage (44). These studies in humans are consistent with compelling results in mice that global knockout of the Bmall gene (the only single gene knockout that results in behavioral rhythmicity) causes infertility in both males and females. Male knockout mice were also characterized by low testosterone, high LH, and low FSH, as well as small testes and low sperm count (45).

\section{CIRCADIAN CLOCK DESYNCHRONY DISRUPTS ENDOCRINOLOGY}

In humans, internal desynchronization can be induced by a forced 28-h sleep-wake cycle (8-h sleep, 20-h awake) which is outside the range of entrainment for the human circadian clock. Rhythms of some metabolites such as leptin and glucose predominately follow the 28-h behavioral cycle, while cortisol rhythms follow the 24-h circadian cycle (5), consistent with the idea that the cortisol rhythm is driven by the primary circadian clock in the SCN. After four cycles, this protocol results in circadian misalignment, in which the behavioral sleep-wake cycle is 12 -h out of phase with the circadian cycle. In these misaligned conditions, leptin rhythms are blunted, postprandial glucose and insulin are increased, and cortisol rhythms are $180^{\circ}$ out of phase with the behavioral rhythm. Nearly half of the participants undergoing the 28-h cycle exhibited a pre-diabetic state during circadian misalignment. In field studies of shift work, the phase of the melatonin rhythm in night shift workers exhibits large inter-individual variability even when measured after the last night shift worked in permanent night shifters (46) or after 12 days of night shift (47). 
In one report, cortisol rhythms took five consecutive shifts to adapt to the new behavioral sleep phase, and even then, $25 \%$ of the workers rhythms never adapted (48). Circadian clock-gene expression is rhythmic in human peripheral blood mononuclear cells (PBMCs) (49-52) with $h P E R 1 / 2$ peaking at the sleep-to-wake transition and $h B M A L 1$ peaking at the end of the wake period (53). After 9 days of simulated shift work (forced day-sleep), hPER1/2 rhythms from PBMCs are fully shifted while $h B M A L 1$ rhythms are not (54). However, it is important to note that after only 3 days of simulated shift work, hPER 1 and $h B M A L 1$ expression rhythms are not fully adjusted (54). Although circadian desynchronization of central and peripheral clocks in the reproductive system has yet to be demonstrated (an important area of future research), the above studies suggest that it is possible that misalignment of reproductive system timing also occurs during shift work. If so, this misalignment may contribute to reproductive dysfunction.

Circadian clock disruption can have deleterious effects on reproduction. Although a common single nucleotide polymorphism in the CLOCK gene (rs1801260) was not significantly associated with endometriosis diagnosis, working night shift greatly increases the risk of this disease. Moreover, women who changed their sleep patterns on days-off were particularly vulnerable (12). This finding is especially compelling for nurses in light of our recent finding that $\sim 97 \%$ of nurses choose to switch their sleeping patterns to some form of nocturnal sleep on days-off (34), as depicted and described in Figure 1. Surprisingly, $\sim 1$ out of 4 night shift nurses chose to switch between days and nights via a $>24$-h sleep deprivation period (the No Sleep strategy). In this sample, sleep deprivation commonly occurred just before the first work day, which could impair performance and alertness on the job. Nurses adopting the No Sleep strategy indicated the lowest adaptation levels (in terms of sleep routine regularity and fatigue) to their current shift schedule of 7:00 p.m. to 7:00 a.m. Interestingly, routinely switching sleep/wake patterns may also contribute to irregular menstrual cycles, as noted in several studies $(55,56)$. Specifically, a survey study of reproductive issues in hospital nurses showed that over half of the nurses working nights or rotating shifts complain of painful and irregular menstrual cycles, including changes in the cycle length, menstrual flow, dysmenorrhea, or duration of menstrual bleeding. In addition, a significantly larger percentage of Taiwanese hospital nurses with fixed night shift schedules report menstrual cycles of less than 25 days (57). Likewise, rotating hospital nurses are more likely to have irregular menstrual cycles than permanent day shift nurses (58). In a previous cohort, this same group of researchers found that rotating shift nurses reported variability in menstrual cycle length (some of which were over 33 days). Since lengthening of the menstrual cycle is associated with the length of the follicular phase, these results suggest rotating shift work may induce a delay in ovulation (59). This result is consistent with the classical study in rodent models, in which prevention of the LH surge during the critical circadian window will delay estrus until the same time on the following day (60). More recently, data from the very large cross-sectional Nurses Health Study indicated that the increased length of rotating shift work is significantly associated with a higher relative risk of irregular, extremely long, or extremely short menstrual cycles, after adjustment for contributing covariates (11). Unfortunately, this study was not designed to distinguish rotating shift work from night shift work. Altogether, these results in shift workers are consistent with the interpretation that environmental disruption of the circadian clock has deleterious effects on women's reproductive health.

There are some data suggesting that the circadian-regulated pineal hormone melatonin has an antagonistic relationship with the gonadal hormones. Given that melatonin is critical for
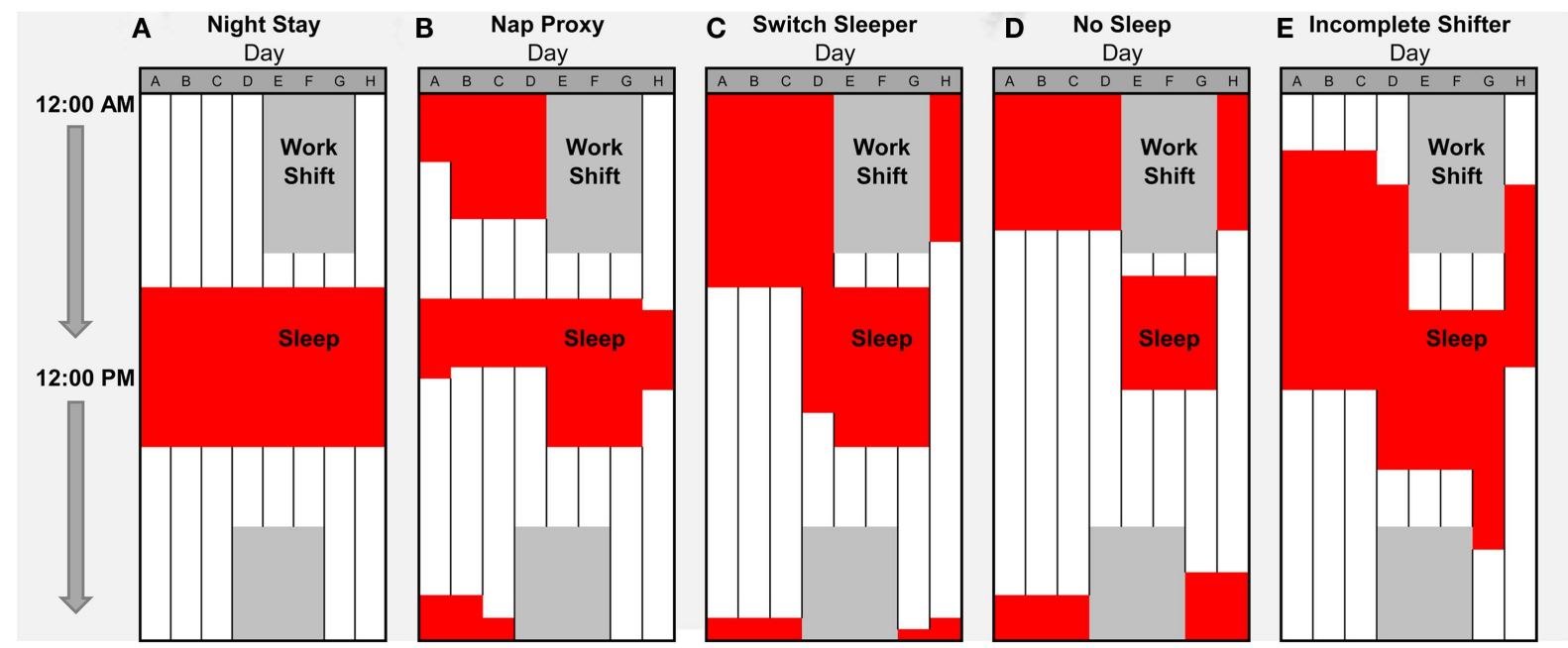

FIGURE 1 | Self-selected sleep strategies for night shift work weeks in nurses. We recently characterized off-shift behavioral sleep strategies of full-time, primarily European-American nurses at Vanderbilt University Medical Center (VUMC) who completed a self-report survey (34), including a typical work-week schedule for night shift at Vanderbilt Hospital for which nurses indicated typical sleep times. (A-E) Five representative strategies for days-off (and percentage among night shift workers) were: (A) Night Stay (2.4\%); (B) Nap Proxy (12.2\%); (C) Switch Sleeper (49.2\%); (D) No Sleep (24.3\%); and (E) Incomplete Switcher (11.9\%). Red indicates sleep times and dark gray indicates night shift schedule from 7:00 p.m. to 7:00 a.m. on Days D-G. Surprisingly, $\sim 1$ out of 4 night shift nurses chose to switch between days and nights via a $>24-h$ sleep deprivation period (the No Sleep strategy). 
signaling seasonal day length and the onset of winter-like inhibition of reproductive function in most photoperiodic animals, it is not entirely surprising that melatonin can be inversely related to estrogen levels (61). Specifically, melatonin can interact with gonadal rhythms as evidenced by (i) melatonin-induced augmentation of the LH surge and (ii) reduced ovarian activity in short day-length environments characterized by increased nocturnal melatonin (62). Finally, a clinical trial of melatonin therapy in perimenopausal and menopausal women with low, medium, and high nocturnal melatonin showed that administration of melatonin reduced $\mathrm{LH}$ and FSH of women with initial low melatonin (63). This apparent antagonistic relationship between melatonin and gonadotropins, taken together with the correlated cortisol awakening response and LH surge, suggest that misalignment of cortisol and melatonin rhythms during shift work $(46,47)$ could be an underlying mechanism for impaired fertility and dysregulated menstrual cycles.

\section{CIRCADIAN REGULATION OF PREGNANCY CIRCADIAN CLOCK CONTROL OF PREGNANCY HORMONES}

During the third trimester, pregnant women normally exhibit significant daily variation in plasma adrenocorticotropic hormone (ACTH), cortisol, and progesterone, but not corticotrophin releasing hormone $(\mathrm{CRH})$ or estradiol, as reported by Magiakou et al. (64). These authors suggested that during late pregnancy, mild hypercortisolism (although still rhythmic) results from a placental CRH positive feedback loop. Circadian regulation of the HPA axis during pregnancy is consistent with circadian regulation of the clock-controlled plasminogen activator inhibitor 1 (important for embryonic development), uterine circadian clock-gene regulation, and maternal placental circadian clock-gene regulation in rodent models (8). In addition to the role of the circadian clock in regulating the HPA axis during pregnancy, the clock may also play an important role in maintaining blood pressure homeostasis during pregnancy. Specifically, timed administration of low doses of acetylsalicylic acid (aspirin) in a double blind, randomized clinical trial has been successful in treating pregnant women with a high risk of developing pre-eclampsia (65). Specifically, women who were given daily doses of acetylsalicylic acid $8 \mathrm{~h}$ after waking or just before bed time were less likely to develop pre-eclampsia/gestational hypertension or to have a pre-term delivery than those who took daily doses immediately after waking. In addition, the later time of administration significantly and reversibly reduced blood pressure during pregnancy. Importantly, mothers with afternoon/evening treatment with acetylsalicylic acid gave birth to infants with significantly greater gestational age and higher birth weight. Taken together, these studies suggest that circadian regulation of HPA axis function and blood pressure are important factors during pregnancy.

\section{SHIFT WORK-INDUCED CIRCADIAN DESYNCHRONY DURING PREGNANCY}

Several studies have examined the impact of shift work on maternal health and pregnancy outcomes. In general, shift work (especially rotating work or irregular hours) during pregnancy is associated with pre-term birth, low birth weight, and higher risk of spontaneous abortion or miscarriage (66). Although one previous study noted that night shift work does not affect urinary estradiol levels of pregnant hospital nurses $(67,68)$, this within-subjects study of nurses on a rapid rotation shift had too few subjects to be statistically persuasive, and a more recent meta-analysis that examined a large number of subjects found that the pooled risk estimates for pre-term delivery, low birth weight, and small for gestational age births increased with shift work [(15) but see also (14)]. In addition, examination of factory shift workers revealed that persistent rotating shifts led to lower birth weights and those infants in the bottom 20th percentile of birth weight were more likely to be born from mothers who work persistent rotating shifts (69). Despite the clear time-of-day dependency of treating preeclampsia noted above (65), a very large epidemiology study of workers in Taiwan $(>24,000)$ found that working evening or rotating shifts did not increase the risk of gestational hypertension and pre-eclampsia above the risk for non-working mothers (70).

In rodent models, the impact of circadian desynchrony on pregnancy outcome is quite evident from the work of several studies. For example, an early study found that pregnant mice housed on a 22- or 26-h day (which is outside of the range of entrainment for this species) results in a higher incidence of embryo resorption and poor pup survival (71). In addition, repeated 6-h phase advances or delays (a chronic jet lag model) in mice resulted in a significant decrease in the number of full-term pregnancies resulting from successful matings (72). A body of work in rodents has shown an important role for circadian regulation of prolactin in maintaining pregnancy [reviewed in (38)]. Mice with mutations in the Clock gene have insufficient prolactin release, suggesting that disruption of the circadian clock could impact pregnancy outcome through dysregulation of prolactin (38). Finally, circadian dysregulation during pregnancy may not only affect the health of the mother, but may also affect the health of the pup even after maturity. For example, rats that underwent chronic jet lag (12-h shifts) during pregnancy produced pups with metabolic problems such as obesity, hyperleptinemia, and modulation of glucose tolerance/insulin insensitivity (73).

\section{CIRCADIAN REGULATION OF PARTURITION CIRCADIAN/DIURNAL REGULATION OF LABOR/DELIVERY}

Over the years, many studies have noted that either the onset of labor or birth occurs more often at certain times of the day than others. For example, the onset of labor and spontaneous membrane rupture peaks at night between midnight and 4:00 a.m. (74-76). Several factors such as bacterial inflammation of fetal membranes (chorioamnionitis), time between membrane rupture and labor onset, as well as primiparous versus multiparous mothers, can modulate the timing of labor or membrane rupture. For example, if labor occurs within $3 \mathrm{~h}$ of spontaneous membrane rupture, labor is more likely to begin earlier in the day (75). In addition, labor onset in first pregnancies is more likely to occur either in the early evening (i.e., 8:00 p.m.) or early morning (i.e., 8:00 a.m.), and this time-of-day labor onset bimodal rhythm appears to be absent in multiparous pregnancies (77). In contrast to labor onset timing, which is most likely to begin during the night, the timing of births peak during the day around 1:00-2:00 p.m. for primiparous births and slightly earlier for multiparous births (i.e., 


\section{Known circadian regulated processes}

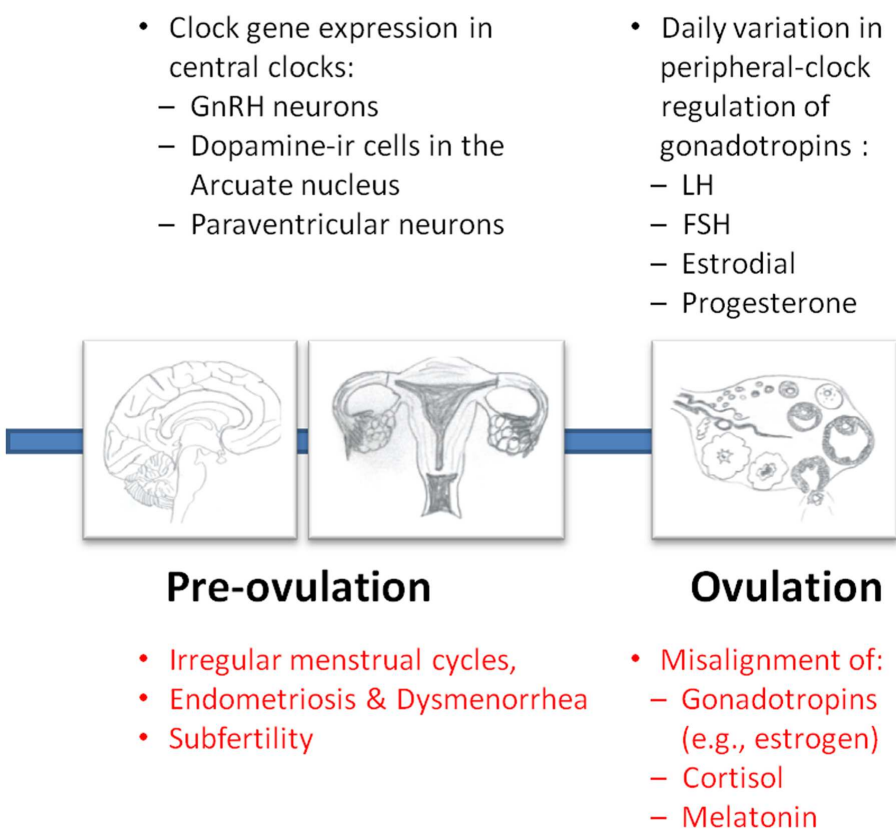

- Clock gene expression in central clocks:

- GnRH neurons

- Dopamine-ir cells in the

Arcuate nucleus

- Paraventricular neurons
- Daily variation in hypothalamic pituitary axis:

- ACTH

- Cortisol

- Chronotherapeutic success for preeclampsia
- Daily variation in:

- Spontaneous membrane rupture

- Labor onset

- Birth time

- Seasonal variation in birth date.

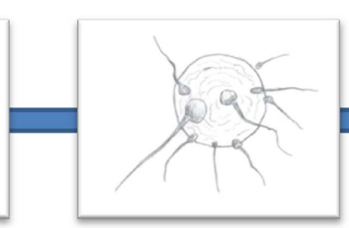

Pregnancy

- Spontaneous abortion

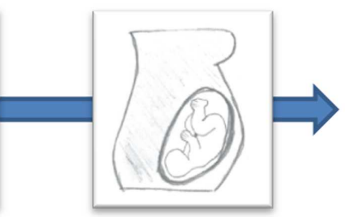

Parturition
- Preterm birth

- Low birth weight

- Reduced breastfeeding success

\section{Dysfunction associated with shift-work}

FIGURE 2 | Circadian regulation of reproduction and impairment associated with shift work. Evidence suggests that the circadian clock regulates each part of the reproductive axis from timing of neuronal activity in hypothalamic neurons to the day-night variation in the release of pregnancy hormones. Dysregulation of circadian rhythms, as often occurs with shift work, results in increased risk of adverse consequences at each step of the reproductive pathway. See text for references. $\mathrm{GnRH}$, gonadotropin releasing hormone; $\mathrm{LH}$, luteinizing hormone; FSH, follicle stimulating hormone; $\mathrm{ACTH}$, adrenocorticotropic hormone. early morning) (78). Finally, there may be seasonal rhythms - for example, one study noted that births are more common from September to November compared to the winter months (December to February) (78).

Given these temporal differences in parturition, it is not surprising that several studies have found that some interventions during labor are more successful at certain times of the day than others. For example, one study conducted a nested, randomized, controlled clinical trial comparing morning (8:00 a.m.) versus evening (8:00 p.m.) administration of prostaglandin and its success rate in inducing labor. While there were no differences in whether or not birth occurred within $24 \mathrm{~h}$ of induction or whether or not a cesarean delivery was used, morning inductions required less oxytocin, had a shorter induction to birth interval, and were less likely to result in instrumental vaginal births for women in their first pregnancies (79). However, it is important to note that a recent meta-analysis of perinatal mortality found no overall difference between morning and evening prostaglandin application or oxytocin-delivery in either maternal or neonatal outcomes (80). The day/night profile of melatonin secretion is one putative underlying mechanism for time-of-day differences in labor and delivery or in the success rate of labor intervention. A recent review highlights this potential role for melatonin, noting that melatonin and oxytocin work in concert to induce contraction of smooth muscle myometrial cells in the uterus (81).

\section{CIRCADIAN DYSFUNCTION AND LABOR/DELIVERY}

In people, sleep and circadian disruption induced by shift work can affect labor and pregnancy outcome. For example, severely disrupted sleep during late pregnancy is more likely to result in cesarean delivery, and even sleep restriction to less than 6] per night is sufficient to increase the risk of long labor and cesarean delivery. Interestingly, fatigue during labor and delivery is not an underlying factor (82). In addition, pregnant Chinese textile workers who work rotating shifts are more likely to give birth at younger gestational ages and to infants with a low birth weight (83), consistent with the Swedish Midwife Study, which found that night work is significantly associated with pre-term birth and small for gestational age births (84). Overall, this link between shift work and pregnancy outcome is consistent with findings in mice with genetic knockout of the Clock gene. Only $57 \%$ of these mutant mice deliver viable pups and the rest either reabsorb their pups or go into a long, extended labor that does not end in delivery (85). 
Finally, even after birth, shift work can impact new moms' ability to breastfeed. One study found that breastfeeding rates among night shift workers are reduced at 1 month and 2 months after birth (16).

\section{CONCLUSION AND SUGGESTIONS}

In summary, there is a growing amount of evidence supporting the notion that the circadian clock is involved in regulation of nearly every part of the reproductive pathway. For example, circadian clock-gene expression has been localized to neuroendocrine centers in the brain (e.g., hypothalamic GnRH neurons and pituitary cells) and reproductive tissues (e.g., ovary, fallopian tube, uterus), and shown to be necessary for the proper regulation of prolactin, gonadotropins (e.g., LH and FSH), and the GnRH-receptor. Moreover, day-night variation in blood pressure during pregnancy, and timing of labor and/or birth suggest the involvement of the circadian clock. Thus, it is conceivable that perturbations of the circadian system misalign hormones and gonadotropins during the reproductive cycle in a shift work environment. In turn, this can lead to interference with menstrual cycles, pregnancy, and parturition, resulting in increased risk of infertility, spontaneous abortions, pre-term births, low birth weights, and difficulty breastfeeding (Figure 2). While documenting these hazards of shift work is an important ongoing mission, it is now imperative for future studies to empirically show how shift work creates circadian misalignment of gonadotropins and other endocrine hormones in humans. The ultimate goal is to determine how to reduce this misalignment and the consequential pathologies. Given that many

\section{REFERENCES}

1. Sleep in America Poll. Washington, DC: National Sleep Foundation (2008) [cited 2008 Mar 3]. Available from: http://www.sleepfoundation. org/sites/default/files/2008\% 20POLL\%20SOF.PDF

2. U.S.D.O.L. Workers on Flexible and Shift Schedules in May 2004. US Department of Labor. (2005). Available from: http://www.bls.gov/ news.release/pdf/flex.pdf

3. Boivin DB, Tremblay GM, James FO. Working on atypical schedules. Sleep Med (2007) 8(6): 578-89. doi:10.1016/j.sleep.2007. 03.015

4. Foster RG, Wulff K. The rhythm of rest and excess. Nat $\mathrm{Rev} \mathrm{Neu}$ rosci (2005) 6(5):407-14. doi:10. 1038/nrn1670

5. Scheer FA, Hilton MF, Mantzoros CS, Shea SA. Adverse metabolic and cardiovascular consequences of circadian misalignment. Proc Natl Acad Sci U S A (2009) 106(11):4453-8. doi:10.1073/pnas. 0808180106

6. Chen JD, Lin YC, Hsiao ST. Obesity and high blood pressure of 12-hour night shift female clean-room workers. Chronobiol Int (2010) 27(2):334-44. doi:10.3109/ 07420520903502242
7. Schernhammer ES, Laden F, Speizer FE, Willett WC, Hunter DJ, Kawachi I, et al. Rotating night shifts and risk of breast cancer in women participating in the nurses' health study. J Natl Cancer Inst (2001) 93(20):1563-8. doi:10.1093/jnci/93. 20.1563

8. Kennaway DJ, Boden MJ, Varcoe TJ. Circadian rhythms and fertility. Mol Cell Endocrinol (2012) 349(1):56-61. doi: 10.1016/j.mce.2011.08.013

9. Boden MJ, Kennaway DJ. Circadian rhythms and reproduction. Reproduction (2006) 132(3):379-92. doi: 10.1530/rep.1.00614

10. Mahoney MM. Shift work, jet lag, and female reproduction. Int J Endocrinol (2010) 2010:813764. doi:10.1155/2010/813764

11. Lawson CC, Whelan EA, Lividoti Hibert EN, Spiegelman D, Schernhammer ES, Rich-Edwards JW. Rotating shift work and menstrual cycle characteristics. Epidemiology (2011) 22(3):305-12. doi:10.1097/ EDE.0b013e3182130016

12. Marino JL, Holt VL, Chen C, Davis S. Shift work, hCLOCK T3111C polymorphism, and endometriosis risk. Epidemiology (2008) 19(3):477-84. doi: 10.1097/EDE.0b013e31816b7378

shift workers revert to nocturnal sleep patterns on days-off (34), entrainment of endocrine rhythms to night shift is not likely a viable solution. Attention to off-shift behavioral sleep strategies and determination of which strategies produce the least amount of misalignment of circadian clock-controlled rhythms (including reproductive hormones) could lead to potential solutions to the reproductive hazards of shift work. For example, in our study of nurses on night shift, we identified five different sleep/wake schedules that nurses had themselves selected (described in Figure 1). Based on self-reported adaptation and performance, we suggest that strategies such as "Incomplete Shifter" or "Switch Sleeper" be implemented to minimize the loss of performance due to sleep deprivation. Tests of these sleep/wake strategies for their impact on the reproductive system could identify schedules that minimize the shift work-induced disruptions in the reproductive axis reviewed in this paper.

\section{ACKNOWLEDGMENTS}

This work was supported by the National Institutes of Health [R00GM-086683 (Karen L. Gamble), R01NS-082413 (Karen L. Gamble), R21HL102492 (Carl Hirschie Johnson), R01GM067152 (Carl Hirschie Johnson), and R01GM088595 (Carl Hirschie Johnson)], and the UAB Center for Clinical and Translational Science (UL1 TR-000165) from the National Center for Advancing Translational Sciences (NCATS) and National Center for Research Resources (NCRR) component of the National Institutes of Health (NIH).

13. Cone JE, Vaughan LM, Huete A, Samuels SJ. Reproductive health outcomes among female flight attendants: an exploratory study. $J$ Occup Environ Med (1998) 40(3): 210-6. doi:10.1097/00043764199803000-00002

14. Rocheleau CM, Lawson CC, Whelan EA, Rich-Edwards JW. Shift work and adverse pregnancy outcomes: comments on a recent metaanalysis. BJOG (2012) 119(3):378; author reply 9-80 doi:10.1111/j. 1471-0528.2011.03211.x

15. Bonzini M, Palmer KT, Coggon D, Carugno M, Cromi A, Ferrario MM. Shift work and pregnancy outcomes: a systematic review with meta-analysis of currently available epidemiological studies. BJOG (2011) 118(12):1429-37. doi:10. 1111/j.1471-0528.2011.03066.x

16. Lakati A, Binns C, Stevenson M. The effect of work status on exclusive breastfeeding in Nairobi. Asia Pac J Public Health (2002) 14(2):85-90. doi:10.1177/101053950201400206

17. Dibner C, Schibler U, Albrecht U. The mammalian circadian timing system: organization and coordination of central and peripheral clocks. Annu Rev Physiol (2010) 72:517-49. doi:10.1146/annurevphysiol-021909-135821
18. Sellix MT, Menaker M. Circadian clocks in mammalian reproductive physiology: effects of the "other" biological clock on fertility. Discov Med (2011) 11(59):273-81.

19. Takahashi JS, Hong HK, Ko $\mathrm{CH}$, McDearmon EL. The genetics of mammalian circadian order and disorder: implications for physiology and disease. Nat Rev Genet (2008) 9(10):764-75. doi:10.1038/ nrg2430

20. Leclerc GM, Boockfor FR. Pulses of prolactin promoter activity depend on a noncanonical Ebox that can bind the circadian proteins CLOCK and BMAL1. Endocrinology (2005) 146(6): 2782-90. doi:10.1210/en.20050100

21. Resuehr D, Wildemann U, Sikes $\mathrm{H}$, Olcese J. E-box regulation of gonadotropin-releasing hormone $(\mathrm{GnRH})$ receptor expression in immortalized gonadotrope cells. Mol Cell Endocrinol (2007) 278(1-2):36-43. doi: 10.1016/j.mce.2007.08.008

22. Resuehr HE, Resuehr D, Olcese J. Induction of mPerl expression by $\mathrm{GnRH}$ in pituitary gonadotrope cells involves EGR-1. Mol Cell Endocrinol (2009) 311(1-2):120-5. doi:10.1016/j.mce.2009.07.005 
23. Sellix MT, Menaker M. Circadian clocks in the ovary. Trends Endocrinol Metab (2010) 21(10):628-36. doi: 10.1016/j.tem.2010.06.002

24. Schmidt TM, Do MT, Dacey D, Lucas R, Hattar S, Matynia A. Melanopsin-positive intrinsically photosensitive retinal ganglion cells: from form to function. $J$ Neurosci (2011) 31(45):16094-101. doi:10. 1523/JNEUROSCI.4132-11.2011

25. Tamarkin L, Reppert SM, Klein DC. Regulation of pineal melatonin in the Syrian hamster. Endocrinology (1979) 104(2):385-9. doi:10.1210/ endo-104-2-385

26. Klein DC, Weller J. Input and output signals in a model neural system: the regulation of melatonin production in the pineal gland. In vitro (1970) 6(3):197-204. doi:10.1007/ BF02617764

27. Damiola F, Le Minh N, Preitner N, Kornmann B, Fleury-Olela F, Schibler U. Restricted feeding uncouples circadian oscillators in peripheral tissues from the central pacemaker in the suprachiasmatic nucleus. Genes Dev (2000) 14(23):2950-61. doi:10.1101/gad.183500

28. Gamble KL, Young ME. Metabolism as an integral cog in the mammalian circadian clockwork. Crit Rev Biochem Mol Biol (2013). doi:10.3109/10409238. 2013.786672. [Epub ahead of print].

29. Lee ML, Swanson BE, de la Iglesia HO. Circadian timing of REM sleep is coupled to an oscillator within the dorsomedial suprachiasmatic nucleus. Curr Biol (2009) 19(10):848-52. doi:10.1016/j.cub. 2009.03.051

30. Yamazaki S, Numano R, Abe M, Hida A, Takahashi R, Ueda $\mathrm{M}$, et al. Resetting central and peripheral circadian oscillators in transgenic rats. Science (2000) 288(5466):682-5. doi: 10.1126/science.288.5466.682

31. Yoshikawa T, Sellix M, Pezuk P, Menaker M. Timing of the ovarian circadian clock is regulated by gonadotropins. Endocrinology (2009) 150(9):4338-47. doi:10. 1210/en.2008-1280

32. Davidson AJ, Sellix MT, Daniel J, Yamazaki S, Menaker M, Block GD. Chronic jet-lag increases mortality in aged mice. Curr Biol (2006) 16(21):R914-6. doi:10.1016/ j.cub.2006.09.058

33. Castanon-Cervantes $\mathrm{O}$, $\mathrm{Wu} \mathrm{M}$, Ehlen JC, Paul KN, Gamble KL, Johnson RL, et al. Dysregulation of inflammatory responses by chronic circadian disruption. J Immunol
(2010) 185(10):5796-5805. doi:10. 4049/jimmunol.1001026

34. Gamble KL, Motsinger-Reif AA, Hida A, Borsetti HM, Servick SV, Ciarleglio CM, et al. Shift work in nurses: contribution of phenotypes and genotypes to adaptation. PLoS ONE (2011) 6(4):e18395. doi:10. 1371/journal.pone.0018395

35. Aschoff J. Circadian rhythms in man. Science (1965) 148(3676):1427-32. doi 10.1126/science.148.3676.1427

36. Cahill DJ, Wardle PG, Harlow CR, Hull MG. Onset of the preovulatory luteinizing hormone surge: diurnal timing and critical follicular prerequisites. Fertil Steril (1998) 70(1):56-9. doi:10. 1016/S0015-0282(98)00113-7

37. Kerdelhue B, Brown S, Lenoir V, Queenan JT Jr, Jones GS, Scholler $\mathrm{R}$, et al. Timing of initiation of the preovulatory luteinizing hormone surge and its relationship with the circadian cortisol rhythm in the human. Neuroendocrinology (2002) 75(3):158-63. doi:10.1159/ 000048233

38. Williams WP 3rd, Kriegsfeld LJ. Circadian control of neuroendocrine circuits regulating female reproductive function. Front Endocrinol (Lausanne) (2012) 3:60. doi:10. 3389/fendo.2012.00060

39. Wiegand SJ, Terasawa E. Discrete lesions reveal functional heterogeneity of suprachiasmatic structures in regulation of gonadotropin secretion in the female rat. Neuroendocrinology (1982) 34(6):395-404. doi:10.1159/000123335

40. Bao AM, Liu RY, van Someren EJ, Hofman MA, Cao YX, Zhou JN. Diurnal rhythm of free estradiol during the menstrual cycle. Eur $J$ Endocrinol (2003) 148(2):227-32. doi:10.1530/eje.0.1480227

41. Ahn RS, Choi JH, Choi BC, Kim $\mathrm{JH}$, Lee SH, Sung SS. Cortisol, estradiol-17beta, and progesterone secretion within the first hour after awakening in women with regular menstrual cycles. $J$ Endocrinol (2011) 211(3):285-95. doi:10.1530/ JOE-11-0247

42. Klingman KM, Marsh EE, Klerman EB, Anderson EJ, Hall JE. Absence of circadian rhythms of gonadotropin secretion in women. $J$ Clin Endocrinol Metab (2011) 96(5):1456-61. doi: 10.1210/jc.2010-2739

43. Baumgartner A, Dietzel M, Saletu B, Wolf R, Campos-Barros A, Graf KJ, et al. Influence of partial sleep deprivation on the secretion of thyrotropin, thyroid hormones, growth hormone, prolactin, luteinizing hormone, follicle stimulating hormone, and estradiol in healthy young women. Psychiatry Res (1993) 48(2):153-78. doi: 10.1016/0165-1781(93)90039-J

44. Kovanen L, Saarikoski ST, Aromaa A, Lonnqvist J, Partonen T. ARNTL (BMAL1) and NPAS2 gene variants contribute to fertility and seasonality. PLoS ONE (2010) 5(4):e10007. doi:10.1371/journal.pone.0010007

45. Alvarez JD, Hansen A, Ord T, Bebas P, Chappell PE, Giebultowicz JM, et al. The circadian clock protein BMAL1 is necessary for fertility and proper testosterone production in mice. I Biol Rhythms (2008) 23(1):26-36. doi:10.1177| 0748730407311254

46. Weibel L, Spiegel K, Gronfier C, Follenius $\mathrm{M}$, Brandenberger $\mathrm{G}$ Twenty-four-hour melatonin and core body temperature rhythms: their adaptation in night workers. Am J Physiol (1997) 272(3 Pt 2):R948-54.

47. Boivin DB, James FO. Circadian adaptation to night-shift work by judicious light and darkness exposure. J Biol Rhythms (2002) 17(6):556-67. doi:10.1177/ 0748730402238238

48. Hennig J, Kieferdorf P, Moritz C, Huwe S, Netter P. Changes in cortisol secretion during shiftwork: implications for tolerance to shiftwork? Ergonomics (1998) 41(5):610-21. doi 10.1080/001401398186784

49. Takata M, Burioka N, Ohdo S, Takane H, Terazono H, Miyata M, et al. Daily expression of mRNAs for the mammalian Clock genes Per2 and clock in mouse suprachiasmatic nuclei and liver and human peripheral blood mononuclear cells. Jpn J Pharmacol (2002) 90(3):263-9. doi: 10.1254/jijp.90.263

50. Boivin DB, James FO, Wu A, ChoPark PF, Xiong H, Sun ZS. Circadian clock genes oscillate in human peripheral blood mononuclear cells. Blood (2003) 102(12):4143-5. doi: 10.1182/blood-2003-03-0779

51. Kusanagi H, Mishima K, Satoh K, Echizenya M, Katoh T, Shimizu T. Similar profiles in human period 1 gene expression in peripheral mononuclear and polymorphonuclear cells. Neurosci Lett (2004) 365(2):124-7. doi:10.1016/j. neulet.2004.04.065

52. Teboul M, Barrat-Petit MA, Li XM, Claustrat B, Formento JL, Delaunay F, et al. Atypical patterns of circadian clock gene expression in human peripheral blood mononuclear cells.
J Mol Med (2005) 83(9):693-9. doi: 10.1007/s00109-005-0697-6

53. James FO, Boivin DB, Charbonneau S, Belanger V, Cermakian $\mathrm{N}$. Expression of clock genes in human peripheral blood mononuclear cells throughout the sleep/wake and circadian cycles. Chronobiol Int (2007) 24(6):1009-34. doi:10.1080/ 07420520701800736

54. James FO, Cermakian N, Boivin DB. Circadian rhythms of melatonin cortisol, and clock gene expression during simulated night shift work. Sleep (2007) 30(11):1427-36.

55. Uehata T, Sasakawa N. The fatigue and maternity disturbances of night workwomen. J Hum Ergol (Tokyo) (1982) 11(Suppl):465-74.

56. Labyak S, Lava S, Turek F, Zee P. Effects of shiftwork on sleep and menstrual function in nurses. Health Care Women Int (2002) 23(6-7):703-14. doi: 10.1080/07399330290107449

57. Chung FF, Yao CC, Wan GH. The associations between menstrual function and life style/working conditions among nurses in Taiwan. $J$ Occup Health (2005) 47(2):149-56. doi:10.1539/joh.47.149

58. Wan GH, Chung FF. Working conditions associated with ovarian cycle in a medical center nurses: a Taiwan study. Jpn J Nurs Sci (2012) 9(1):112-8. doi:10.1111/j. 1742-7924.2011.00191.x

59. Lohstroh PN, Chen J, Ba J, Ryan LM, Xu X, Overstreet JW, et al. Bone resorption is affected by follicular phase length in female rotating shift workers. Environ Health Perspect (2003) 111(4):618-22. doi: 10.1289/ehp.5878

60. Everett JW, Sawyer CH. A 24-hour periodicity in the " $\mathrm{LH}$-release apparatus" of female rats, disclosed by barbiturate sedation. Endocrinology (1950) 47(3):198-218. doi:10.1210/ endo-47-3-198

61. Luboshitzky R, Herer P, ShenOrr Z. Cyproterone acetate-ethinyl estradiol treatment alters urinary 6-sulfatoxymelatonin excretion in hyperandrogenic women. Neuro Endocrinol Lett (2002) 23(4):30913 .

62. Bellastella A, Pisano G, Iorio S, Pasquali D, Orio F, Venditto T, et al. Endocrine secretions under abnormal light-dark cycles and in the blind. Horm Res (1998) 49(34):153-7. doi:10.1159/000023163

63. Bellipanni G, Bianchi P, Pierpaoli W, Bulian D, Ilyia E. Effects of melatonin in perimenopausal and menopausal women: a randomized and placebo controlled study. Exp 
Gerontol (2001) 36(2):297-310. doi: 10.1016/S0531-5565(00)00217-5

64. Magiakou MA, Mastorakos G, Rabin D, Margioris AN, Dubbert $\mathrm{B}$, Calogero AE, et al. The maternal hypothalamic-pituitary-adrenal axis in the third trimester of human pregnancy. Clin Endocrinol (Oxf) (1996) 44(4):419-28. doi:10.1046/j. 1365-2265.1996.683505.x

65. Hermida RC, Ayala DE, Iglesias M. Administration time-dependent influence of aspirin on blood pressure in pregnant women. Hypertension (2003) 41(3 Pt 2):6516. doi:10.1161/01.HYP.0000072335. 73748.0D

66. Knutsson A. Health disorders of shift workers. Occup Med (Lond) (2003) 53(2):103-8. doi:10.1093/ occmed/kqg048

67. Yamauchi H. Effects of night work on urinary excretion rates of 6-sulfatoxymelatonin, norepinephrine and estriol in pregnant women. Ind Health (2004) 42(2):268-76. doi:10.2486/indhealth.42.268

68. Yamauchi H, Iwamoto M, Harada N. Physiological effects of shift work on hospital nurses. J Hum Ergol (Tokyo) (2001) 30(1-2):251-4.

69. Lin YC, Chen MH, Hsieh CJ, Chen PC. Effect of rotating shift work on childbearing and birth weight: a study of women working in a semiconductor manufacturing factory. World J Pediatr (2011) 7(2):129-35. doi:10.1007/s12519-011-0265-9

70. Chang PJ, Chu LC, Hsieh WS, Chuang YL, Lin SJ, Chen PC. Working hours and risk of gestational hypertension and pre-eclampsia. Occup Med (Lond) (2010) 60(1):66-71. doi: 10.1093/occmed/kqp119

71. Endo A, Watanabe T. Effects of non-24-hour days on reproductive efficacy and embryonic development in mice. Gamete Res (1989) 22(4):435-41. doi:10.1002/ mrd.1120220409

72. Summa KC, Vitaterna MH, Turek FW. Environmental perturbation of the circadian clock disrupts pregnancy in the mouse. PLoS ONE (2012) 7(5):e37668. doi:10.1371/ journal.pone. 0037668

73. Varcoe TJ, Wight N, Voultsios A, Salkeld MD, Kennaway DJ. Chronic phase shifts of the photoperiod throughout pregnancy programs glucose intolerance and insulin resistance in the rat. PLoS ONE (2011) 6(4):e18504. doi:10.1371/ journal.pone.0018504

74. Cooperstock M, England JE, Wolfe RA. Circadian incidence of labor onset hour in preterm birth and chorioamnionitis. Obstet Gynecol (1987) 70(6):852-5

75. Cooperstock M, England JE, Wolfe RA. Circadian incidence of premature rupture of the membranes in term and preterm births. Obstet Gynecol (1987) 69(6): 936-41.

76. Ngwenya S, Lindow SW. 24 Hour rhythm in the timing of pre-labour spontaneous rupture of membranes at term. Eur J Obstet Gynecol Reprod Biol (2004) 112(2):151-3. doi:10. 1016/S0301-2115(03)00286-0

77. Cagnacci A, Soldani R, Melis GB, Volpe A. Diurnal rhythms of labor and delivery in women: modulation by parity and seasons. Am J Obstet Gynecol (1998) $\mathbf{1 7 8}(1$ Pt 1):140-5. doi:10.1016/S00029378(98)70641-6

78. Mancuso PJ, Alexander JM, McIntire DD, Davis E, Burke G, Leveno KJ. Timing of birth after spontaneous onset of labor. Obstet Gynecol (2004) 103(4):653-6. doi:10.1097/ 01.AOG.0000118309.70035.63

79. Dodd JM, Crowther CA, Robinson JS. Morning compared with evening induction of labor: a nested randomized controlled trial. A nested randomized controlled trial. Obstet Gynecol (2006) 108(2):350-60. doi:10.1097/01.AOG.0000227746. 35565.d9

80. Bakker JJ, van der Goes BY, Pel M, Mol BW, van der Post JA. Morning versus evening induction of labour for improving outcomes. Cochrane Database Syst Rev (2013) 2:CD007707. doi:10.1002/ 14651858.CD007707.pub2

81. Olcese J, Lozier S, Paradise C. Melatonin and the circadian timing of human parturition. Reprod Sci (2013) 20(2):168-74. doi:10.1177/ 1933719112442244

82. Lee KA, Gay CL. Sleep in late pregnancy predicts length of labor and type of delivery. Am J Obstet Gynecol (2004) 191(6):2041-6. doi:10.1016/ j.ajog.2004.05.086
83. Xu X, Ding M, Li B, Christiani DC. Association of rotating shiftwork with preterm births and low birth weight among never smoking women textile workers in China. Occup Environ Med (1994) 51(7):470-4. doi:10.1136/oem.51.7. 470

84. Bodin L, Axelsson G, Ahlborg G Jr. The association of shift work and nitrous oxide exposure in pregnancy with birth weight and gestational age. Epidemiology (1999) 10(4):429-36. doi:10.1097/ 00001648-199907000-00015

85. Miller BH, Olson SL, Turek FW, Levine JE, Horton TH, Takahashi JS. Circadian clock mutation disrupts estrous cyclicity and maintenance of pregnancy. Curr Biol (2004) 14(15):1367-73. doi:10.1016/j.cub. 2004.07.055

86. Prasai MJ, Pernicova I, Grant PJ, Scott EM. An endocrinologist's guide to the clock. J Clin Endocrino Metab (2011) 96(4):913-22. doi:10. 1210/jc.2010-2449

87. Bose S, Boockfor FR. Episodes of prolactin gene expression in GH3 cells are dependent on selective promoter binding of multiple circadian elements. Endocrinol ogy (2010) 151(5):2287-96. doi:10. 1210/en.2009- 1252

88. Olcese J, Sikes HE, Resuehr D. Induction of PER1 mRNA expression in immortalized gonadotropes by gonadotropin-releasing hormone (GnRH): involvement of protein kinase $\mathrm{C}$ and MAP kinase signaling. Chronobio Int (2006) 23(1-2):143-50. doi: $10.1080 / 07420520500521996$

89. Bebas P, Goodall CP, Majewska M, Neumann A, Giebultowicz JM, Chappell PE. Circadian clock and output genes are rhythmically expressed in extratesticular ducts and accessory organs of mice. FASEB J (2009) 23(2):523-33. doi: 10.1096/fj.08-113191

90. Fahrenkrug J, Georg B, Hannibal J, Hindersson P, Gras S. Diurnal rhythmicity of the clock genes Per1 and Per2 in the rat ovary. Endocrinology (2006) 147(8):376976. doi:10.1210/en.2006-0305

91. He PJ, Hirata M, Yamauchi $\mathrm{N}$, Hashimoto S, Hattori MA. The disruption of circadian clockwork in differentiating cells from rat reproductive tissues as identified by in vitro real-time monitoring system. J Endocrinol (2007) 193(3):413-20. doi:10.1677/JOE-07-0044

92. He PJ, Hirata M, Yamauchi

$\mathrm{N}$, Hashimoto S, Hattori MA. Gonadotropic regulation of circadian clockwork in rat granulosa cells. Mol Cell Biochem (2007) 302(1-2):111-8. doi: 10.1007/s11010-007-9432-7

93. He PJ, Hirata M, Yamauchi N, Hattori MA. Up-regulation of Per1 expression by estradiol and progesterone in the rat uterus. JEndocrinol (2007) 194(3):511-9. doi:10.1677/ JOE-07-0172

94. Alvarez JD, Chen D, Storer E, Sehgal A. Non-cyclic and developmental stage-specific expression of circadian clock proteins during murine spermatogenesis. Biol Reprod (2003) 69(1):81-91. doi: 10.1095/biolreprod.102.011833

Conflict of Interest Statement: The authors declare that the research was conducted in the absence of any commercial or financial relationships that could be construed as a potential conflict of interest.

Received: 02 May 2013; paper pending published: 05 June 2013; accepted: 10 July 2013; published online: 07 August 2013. Citation: Gamble KL, Resuehr D and Johnson CH (2013) Shift work and circadian dysregulation of reproduction. Front. Endocrinol. 4:92. doi: 10.3389/fendo.2013.00092

This article was submitted to Frontiers in Systems and Translational Endocrinology, a specialty of Frontiers in Endocrinology.

Copyright (C) 2013 Gamble, Resuehr and Johnson. This is an open-access article distributed under the terms of the Creative Commons Attribution License (CC BY). The use, distribution or reproduction in other forums is permitted, provided the original author(s) or licensor are credited and that the original publication in this journal is cited, in accordance with accepted academic practice. No use, distribution or reproduction is permitted which does not comply with these terms. 